\title{
FACTORS INFLUENCING THE DECISION FOR ABORTION AND NOT USING CONTRACEPTION
}

\author{
Todorka Boeva \\ Department of Health Care, Faculty of public health, Medical University of Varna
}

\begin{abstract}
The problems of reproductive health and sexual behavior provoke an increasing scholarly interest and study in Bulgaria. Research made on the various aspects of sexual behavior shows that abortion is still practiced as a means of regulating the number of children in a family and people are not well informed about the methods of contraception.
\end{abstract}

PURPOSE: To study factors influencing the decision for abortion and those which influence not using contraception.

MATERIALS AND METHODS: The study includes 243 pregnant women from 5 regions in Bulgaria.

The following methods were used: Sociological Methods: Questionnaire method - direct individual anonymous survey among pregnant women who planned the abortion. Documentary method - a literary analysis, studied international experience on the issue. Statistical Methods: SPSS statistical package was used with the main methods for mathematical and statistical analysis: alternative, variance, correlation, graphic.

RESULTS AND DISCUSSION: The demographic profile of the women interviewed during the period February-April, 2014, gives grounds to assert that these are patients of a mean age of 29 years, but with a large age range (between 14-46 years). Only $37 \%$ of them are married, which confirms the tendency for having a children in cohabitation. An inverse correlation between level of education and number of abortions is proven. Every fifth woman said she is unemployed. Based on a quantitative analysis the results show that pregnant women placed first the financial situation as a reason for the termination of an unwanted pregnancy $-22 \%(n=88)$, followed by a reluctance for more children $-18 \%(n=72)$. The feeling that they are not ready yet to bringing a child up is indicated by $11 \%(n=45)$ of the respondents. More than half of the women say that they have made the decision with their partners $(n=123 ; 52 \%)$. However, every third has determined the outcome of the pregnancy alone. Only $9 \%$ reported that a mother had attempted to persuade her to have an abortion. Forty-seven percent of the participants in the study have made the decision for an abortion as soon as they found out about the pregnancy. This suggests a strong desire for pregnancy termination met with a refusal to discuss any alternatives. For nearly half of the women the pregnancy was unwanted, not planned, and probably unexpected. Those who needed a longer period, more than 2 weeks, are $23 \%$. A sig-

\footnotetext{
Address for correspondence:

Todorka Boeva

Medical College, Medical University of Varna

fl. 4 , room 410

84 Tsar Osvoboditel Blvd, Varna

Phone: 0889313411;

e-mail:boevat@mail.bg
}

Received: November 17, 2015

Accepted: June 20, 2016 nificant percentage (24\%) find it difficult to answer. Probably they were faced with the dilemma to keep the pregnancy.

In the present study an important role is given to the research connected with the determining factors influencing the lack of use of contraception among the patients.

CONCLUSIONS: The medical and social problems of abortion require a number of changes in all as- 
pects of the public spheres: a change of the state policy for social support of families, support and creation of family planning offices and schools for parents, changes in the education system with the inclusion of parental involvement, an adequate role of offices at schools in providing information on methods and means of contraception and STDs (STIs) among teenagers, standardization of family planning programs in correspondence to the needs of the modern Bulgarian society.

Keywords: factors, decision, abortion, contraceptives.

\section{INTRODUCTION}

In 2014 , there were 28,145 abortions in medical institutions, i.e. 1360 less compared to 2013. The largest share of them are women aged 20-29 years. From all of abortions $58.7 \%$ are planned. The registered abortions are done mainly in multiprofile hospitals for active treatment $-44.3 \%$. $12.8 \%$ were performed in specialized hospitals for active treatment, $22.5 \%$ - in private hospitals, and $20.3 \%$ - in the medical establishments for outpatient care.

Our country has the most unfavorable ratio of abortions per 1000 births in Europe.

In 2014 in the country 68,083 births have been recorded, of which 67,585 are live births (99.3\%) and 498 - stillbirths. Compared with the previous year, the number of live births has increased by 1007, and the stillbirths - by 15 .

The coefficient of the total birthrate in 2014 was $9.4 \%$, and in the previous $2013-9.2 \%$ (1).

Bulgarian women have their first child at about 27.9 years of age. Summarized data on the number of abortions and births for the country are given in Tabl. 1.
According to the UN report on international developments in 2003, Bulgaria ranks first in number of abortions among girls 15-19 years in Eastern Europe. In our country, 41 of every 1000 girls become mothers at this age, and abortion among teenagers is 35.8 per 1000 . According to the Health Information Center in 2011 - 88 girls under 15 years have had an abortion. The number of teenage girls between 15 and 18 who have interrupted their pregnancy in 2011 is 1 877. According to new research by the National Centre for Protection and Control of Public Health, Bulgaria ranks after Ukraine and Russia in the number of abortions and births of school age (November, 2006) and 37 of every 1000 students have an abortion (1).

In Bulgaria the problems of reproductive health and sexual behavior engendering increasing scientific interest and are being studied. Conducted research on various aspects of sexual behavior indicates that abortion is still practiced as a means of regulating the number of children in the family and people are not well informed about the methods of contraception.

According to prof. Yuliyana Marinova (2) the

Tab. 1. Number of births and abortions

\begin{tabular}{|c|c|c|c|c|c|c|c|}
\hline Year & 2000 & 2005 & 2010 & 2011 & 2012 & 2013 & 2014 \\
\hline \multicolumn{8}{|c|}{ Number } \\
\hline Births & 74234 & 71640 & 76105 & 71402 & 69678 & 67061 & 68083 \\
\hline Abortions & 61378 & 41795 & 31548 & 31716 & 29992 & 29505 & 28145 \\
\hline \multicolumn{8}{|c|}{ Per 1000 women of fertile age } \\
\hline Births & 37.2 & 38.2 & 42.9 & 43.0 & 42.5 & 41.6 & 42.8 \\
\hline Abortions & 30.7 & 22.3 & 17.8 & 19.1 & 18.3 & 18.3 & 17.7 \\
\hline
\end{tabular}

Bulgaria is at one of the first places among the countries with the highest number of abortions, including average number of abortions per woman. sexual culture of young girls and boys in Bulgaria is very low. This is a responsibility of the parents, the educational system and the health care system. Bulgar- 
ia, whose population has decreased catastrophically has a dire need of a program for sex education and protection of the reproductive health of young women. The main priority must be a drastic decrease in the number of planned abortions, because in young women they lead to disability and infertility. Sex education has a key role in reducing the number of abortions among teenagers.

The social environment has influence on women in regard to abortion decision-making. The partner's involvement in the abortion decision was studied in Karuna Chibber's research. She reported that only $31 \%$ of women $(n=954)$ said that male partners had attempted to persuade them to have an abortion. Eleven percent reported that physical violence by a partner is a reason to take such a decision. And 26\% of partners are unwilling or unable to support the woman during her pregnancy or are physically unable to participate in the life of the mother and the future child. The majority (39\%) of women reported, that financial support from the partner is extremely important and indicate its lack as a reason for an abortion. Many respondents estimate that the man next to them "was not responsible enough" to become a father or "he is not ready" and therefore prefer the pregnancy to be terminated. Every fifth woman $(21 \%)$ believes, that "this is not the right man from whom to have a child" and this is the reason to seek an abortion (2).

Wider choice of contraceptive methods is associated with lower fertility and therefore a smaller percentage of abortions. Most of the researches are focused on contraceptive behavior in women. For men there is not enough and specific data. Factors, characterizing the studies are presented in two groups: demographic (age, marital status, education, ethnicity) and a group, including knowledge, attitudes and social influence. Certain authors (3) research the fact why many of the women still use unsafe contraceptive methods, despite the availability of safe ones. This occurs in all demographic groups, but mostly among minors, women over 35 , and women with lower education. The decision for a termination of a pregnancy is a difficult emotional and moral issue of life.

Considering that it is a consequence of an unplanned pregnancy, it can be assumed that it is ac- companied by doubts, fear and guilt. In this study, we search for an answer to the question of which objective life events and factors could be the reason for the decision.

\section{PURPOSE}

To study factors influencing the decision for abortion and those which influence not using contraception.

\section{MATERIAL AND METHODS}

Object of the study are the $\mathbf{2 4 3}$ pregnant women who had a planned abortion at healthcare facilities in the cities of Varna, Dobrich, Shumen, Ruse, Pleven, during a period of three months.

The pregnant women were observed prior to the intervention for a termination of the pregnancy, because their reasons for the decision were already clear.

The survey was conducted in the 8 hospitals with obstetric and gynecological profile, performing abortions (for pregnant women and midwives). The included hospitals were: Multiprofile Hospital for Active Treatment "St. Anna"; Specialized Hospital of Obstetrics and Gynecology for Active Treatment "Prof. Dr. Stamatov"; Medical Center "Dr. P. Cvetkova"; Medical Center "Dr. Walid" in Varna; Multiprofile Hospitals for Active Treatment in Dobrich, Shumen, Ruse and University Hospital for Active Treatment "Georgi Stranski" Pleven. The period of study is three months, covering February, March and April in 2014.

\section{Sociological Methods:}

Questionnaire method - direct individual anonymous survey of the pregnant women. The questionnaire included 24 questions: 19 - closed-ended, 1 semi-closed-ended and 4- identifying (studying age, education, profession, marital status). Documentary method was used as well. It consisted of literary analysis, comparative legal analysis, and studied international experience on the issue.

Statistical methods for processing and analysis of information:

* Descriptive analysis

* Correlation analysis

* Graph analysis 


\section{RESULTS AND DISCUSSION}

The study involved 241 pregnant women from five major cities in the Northeast and North Central regions. Most of the representatives were from Varna - 56\% ( $\mathrm{n}=136)$. The rest were distributed as follows: Shumen - 16\% $(\mathrm{n}=39)$, followed by Dobrich - 15\% ( $=35)$, Ruse - $8 \%(n=19)$, and Pleven - 5\%.

The youngest participant is 14 years old from Varna, and the oldest is 45, from Dobrich. The average age of respondents is 29(133). Most representatives are at an age between 25 and 35 - 55\%. The percentage of women between $14-24$ years of age is $26 \%$, while those from 36 to 45 are $18 \%$.

A significant part (70\%) of the respondents have a job, while the unemployed are 17 (5\%), including 26 unemployed and 9 housewives. Twelve women (5\%) are still studying, of them 17 are university students and 8 - schoolgirls.

In the study, most participants are with a secondary education - $49 \%$, followed by such with a bachelor's degree - $20 \%$. The lowest is the number of those with a master's degree $-13 \%$, and the percentage of women with primary education is $18 \%$.

The survey participants who are married are $37 \%$ of the total number. With equal share are the participants who are single, and those who live with their partners without being married $-31 \% .1 \%$ of the participants have given another response.

The largest share was of women with two children $-31.5 \%$. The share of women with one child and those without any is equal $-29.9 \%$. The lowest percentage of the interviewed is such with three or more children $-8.7 \%$.

A link between the number of births and age of participants is revealed by ANOVA $(\mathrm{F}=6.213$, $\mathrm{p}$ $<0.05)$. The connection is direct and has a statistical significance, $r=0.607, \mathrm{p}<0.01$.

Eighty-nine women (37\%) prefer not to answer the question about the number of previous pregnancies which ended in abortion. Respondents with one abortion are $58.6 \%$ of the total number, followed by those with two prior ones $-27 \%$ and those with three abortions - 9.9\%. A small part has undergone four abortions - $2 \%$, and $1.3 \%$ - seven. The relative share of women with six to eight treatments comes down to $0.7 \%$ (Fig. 1).

\section{Number of previous abortions}

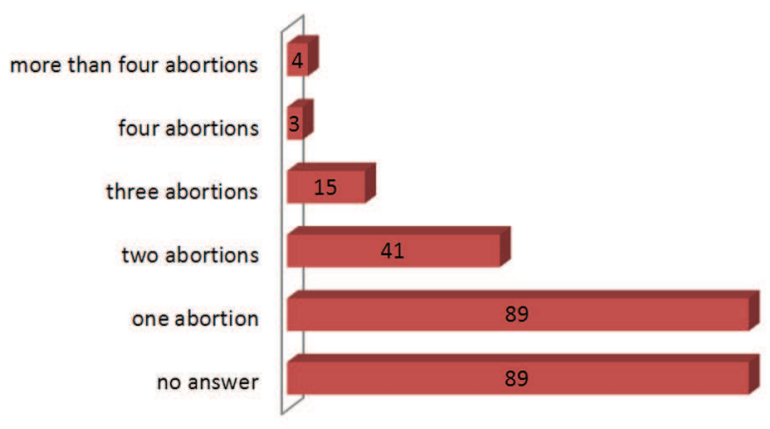

Fig. 1. Number of previous abortions (in absolute numbers)

A link between the number of births and the number of pregnancies ended in abortion is determined by using dispersion analysis $(\mathrm{F}=3.195 ; \mathrm{p}$ $<0.05)$. A correlation analysis reveals weak and direct connection $\mathrm{r}=0.294 \mathrm{p}<0.01$.

These results are alarming and show that there still is a lack of knowledge about the methods of contraception which can guide the behavior of the women at a reproductive age. It is necessary to introduce routine post-abortion counseling for women using abortion, as a means of family planning.

We determined a connection between the number of pregnancies which ended in abortion and the level of education of the participants $(\mathrm{F}=4.821$; $\mathrm{p}<0.05)$. The connection is weak and $\mathrm{r}=-0.241 ; \mathrm{p}<$ 0.01 . Women who have had four to six abortions have only primary education. Most of the women with one abortion have higher education.

Pregnant women (patients) indicated the financial situation as the main reason for the termination of an unwanted pregnancy (22\%), followed by reluctance for more children - $18 \%$.

This proves a known connection between income and reproductive intentions. Modern parents would like to create better opportunities for their children, which is associated with higher economic status. This confirms the idea that social status is directly related to the birth and raising a child and a policy related to the promotion of birth must be consistent with this.

The feeling, that they are not ready yet to raise a child is indicated by $11 \%$ of the respondents whose mean age is 24 . 
Every tenth woman who continued her studies stated academic duty as a reason for abortion. $9 \%$ of the respondents mentioned a residential problem, an equal number (9\%) prefer their career growth to the birth of child. Relationships with partners are mentioned by $8 \%$, followed by health problems $-7 \%$ and a lack of family support - 6\% (Fig. 2).

More than half of the women say that they have made the decision together with their partners (52\%). Every third, however, determined the outcome of the pregnancy alone. Participation of their mothers with advice and influence is shared by $9 \%$ of the respondents. Only $2 \%$ have trusted their friends' opinion.

\section{Factors influencing the decision for abortion}

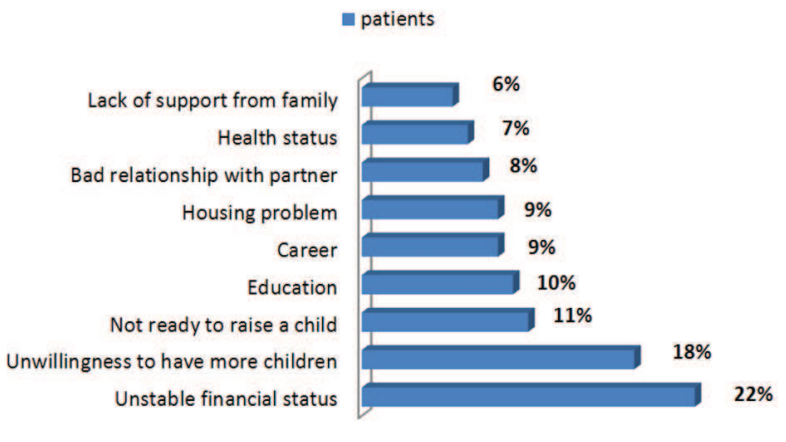

Fig. 2. Factors influencing the decision for abortion

Forty-seven percent of the participants in the study made the decision for an abortion as soon as they found out about the pregnancy. This suggests a strong desire for pregnancy termination and was met with a refusal to discuss the alternatives. For nearly half of women the pregnancy is unwanted, not planned and probably unexpected. An uncompromising decision taken quickly indicates a strong motivation for abortion. Those who needed a longer period, more than 2 weeks, are $23 \%$ of the total participants. A significant share $(24 \%)$ of the respondents has found it difficult to answer. It is possible that they were faced with the dilemma to keep the pregnancy.

More than half of women say that they have made the decision with the agreement and support of the father of the child. This corresponds to the modern trends where both partners are present during the births of their children and have equal roles in decisions relating to their number. This is not influ- enced by marital status (marriage or cohabitation). This trend follows the attitude that both sexes are equal, with equal rights and responsibilities.

The fact that the majority of the patients believe they are familiar with the methods of contraception is satisfactory (84\%). Women who are not confident in their knowledge are $9 \%$ of the total number, and $7 \%$ gave a negative answer. This is seemingly at odds with the high level of abortions, which would be very low if the effective methods were used. The conclusion to be made is that there is a discrepancy between behavior and knowledge i.e. "It is known, but not applicable" (Fig. 3).

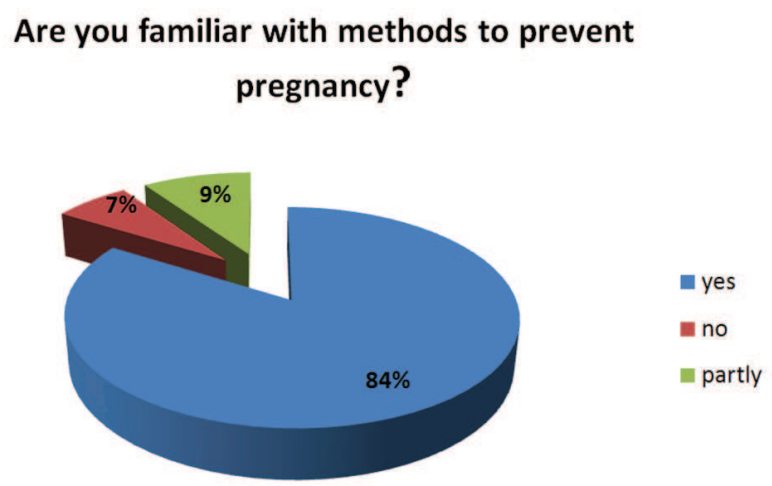

Fig. 3. Contraceptive knowledge

In response to the question whether they use contraception, $37 \%$ of the surveyed patients confirmed using such, those who only sometimes do are $35 \%$ of the total, and nearly one third (28\%) do not use any methods to prevent unwanted pregnancies.

There is a relationship between knowledge about contraceptive methods and their use, which is statistically significant $(\chi 2=23.846, \mathrm{p}<0.05)$. The strength of the relationship can be described as weak, $\mathrm{r}=0.193, \mathrm{p}<0.01$. The majority of the women who are familiar with the methods use them.

The risk of occurrence of unwanted pregnancy is undoubtedly greater in women not using any contraceptive methods. There is a real risk from the improper use of different means of contraception.

Counseling on issues of family planning should be done before and after the decision to terminate the unwanted pregnancy. This would improve the readiness for future use. 
A $\chi 2$ analysis reveals a statistically significant relationship between knowledge of methods to prevent pregnancy and education $\left(\chi^{2}=73.424 \mathrm{p}<0.05\right)$ The relationship is moderate and direct $r=0.372$, $\mathrm{p}<0.01$. Only in the group of women with higher education, whether with a bachelor's or a master's degree, did all respondents indicate that they are aware of various contraceptive methods.

A positive trend is that after the abortion the rate of women who intend to use preventive measures is significant - 78\%. A small part (17\%) of the respondents are not sure whether they will take contraceptives, and even fewer are those who would not use them - $4 \%$. Women who decided on something different are only $1 \%$ (Fig. 4).

\section{Do you intend to use contraception after an abortion?}

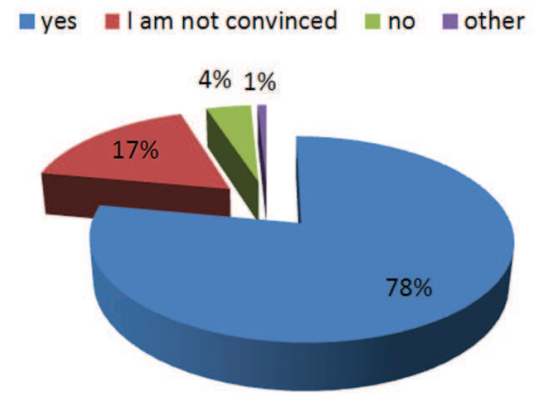

Fig .4. Attitude use contraception after abortion

A statistically significant correlation between the use of preventive measures in general and their use after abortions is determined ( $\chi^{2}=42.558$ is, $p$ $<0.05)$. The strength of the connection is very weak $r$ $=0.161, \mathrm{p}=0.014$. Most of women who do not use protective equipment, plan to begin after the abortion.

\section{CONCLUSIONS}

The medical and social problems of abortions require a number of changes in all aspects of the public spheres: changing of state policy for social support for families, support and creation of family planning offices and schools for parents, changes in the education system with the inclusion of parental involvement, an adequate role of offices at schools to provide information on methods and means of contraception and STDs (STIs) among teenagers, standard- ization of family planning programs corresponding to the needs of the modern Bulgarian society.

Training for health professionals on contraceptive counseling is needed. Provision of information materials about methods of contraception is required as well.

\section{REFERENCES}

1. Healthcare 20015r. www.nsi.bg

2. Marinova Yuliyana, Abortion. Stara Zagora, Trakia University, 2001

3. Facts on Induced Abortion in the United States national overview fact sheet; mediaworks@guttmacher.org

4. Chibber Karuna., TheRole of Intimate Partnersin Women's Reasons for Seeking Abortion, Women's Health Issues 24-1 (2014) pp.131-138

5. Vasilev, N. Family Planning: A Guide for health professionals. Sofia 2001

6. Guide for service providers in the field of sexual and reproductive health, BASP, 2004

7. Bostandzhiev, Rumen "Sexology and family planning”, “Znanie” 2000 